\title{
Analisis Standar Desain Universal Pada Fasilitas Toilet Studi Kasus Stasiun Kereta Api Gambir
}

\author{
Jonathan $^{1}$, Erleoando Tanujaya ${ }^{2}$, Oka Leonardy $^{3}$, Noeratri Andanwerti ${ }^{4}$ \\ Fakultas Seni Rupa dan Desain, Universitas Tarumanagara \\ jonathan.615140145@stu.untar.ac.id
}

\begin{abstract}
Abstrak - Stasiun Kereta Api Gambir merupakan salah satu landmark kota Jakarta, dengan tingkat intensitas penggunaan yang tinggi. Penelitian ini bertujuan untuk mengetahui apakah fasilitas pada toilet stasiun kereta api sudah dapat digunakan oleh semua orang secara maksimal. Metode yang dilakukan adalah kualitatif berdasarkan kriteria standar desain universal. Hasil penelitian menunjukkan bahwa: (1) Peningkatan pada fasilitas toilet kereta api Gambir belum memenuhi standar desain universal; (2) Terdapatnya signage untuk disabilitas tanpa adanya toilet untuk disabilitas. Dari hasil penelitian ini dapat disimpulkan bahwa perubahan yang dilakukan oleh PT. KAI belum memenuhi tuntutan dari desain universal karena ketiadaan toilet khusus untuk pengguna difabel.
\end{abstract}

Kata kunci: Desain universal, difabel, fasilitas toilet, stasiun Gambir, kereta api.

\section{PENDAHULUAN}

Desain universal menurut Ron Mace dalam publikasinya yang berjudul Accessible Adaptable, and Universal Design, adalah upaya dalam produk dan lingkungan yang kegunaannya diperuntukkan bagi semua orang, dalam cakupan yang seluas mungkin, tanpa memerlukan adaptasi berlebih dan desain khusus. Cangkupan yang dimaksud pada desain universal membuat kegunaan produk dan lingkungannya dapat digunakan oleh semua orang. Dalam hal ini toilet menjadi salah satu cangkupan kecil dari desain universal.

Toilet adalah fasilitas sanitasi untuk tempat buang air besar maupun kecil, tempat cuci tangan dan muka. Menurut Kamus Besar Bahasa Indonesia, sanitasi adalah usaha untuk membina dan menciptakan suatu keadaan yang baik di bidang kesehatan, terutama kesehatan masyarakat.

Pada tahun 2016 lalu, PT Kereta Api Indonesia (Persero) (KAl) melakukan pembenahan pada fasilitas toilet yang ada di stasiun Gambir Jakarta Pusat. Akan tetapi pembenahan yang dilakukan belum memadahi karena tidak adanya fasilitas toilet yang dapat digunakan untuk anak kecil dan orang-orang berkebutuhan khusus.

Masalah dari penelitian ini adalah untuk mengetahui kesesuaian fasilitas toilet di stasiun kereta api Gambir dengan kriteria desain universal agar dapat menjadi rujukan dan bahan pembelajaran untuk lebih diperhatikan agar setiap orang dapat menggunakan fasilitas toilet di stasiun kereta api Gambir dengan maksimal. 
Penelitian serupa mengenai desain universal yang dilakukan oleh Keumala (Keumala, 2016), menunjukkan bahwa persepsi difabel terhadap tingkat kemandirian berpengaruh secara positif dengan adanya konsep desain universal pada desain bangunan masjid.

Hasil dari penelitian lain yang dilakukan Yanti (Yanti, 2018) menyatakan bahwa ditemukan adanya beberapa elemen bangunan di kampus terpadu UNISA (Universitas Aisyiyah Yogyakarta) yang belum aksesible, namun beberapa sudah memenuhi standar aksesibilitas.

Penelitian-penelitian mengenai desain universal menunjukkan bahwa terutama ruang-ruang public menuntut penerapan prinsip dan kriteria desain universal sehingga pengguna dari semua kalangan termasuk difabel memiliki aksesibilitas yang sama.

\section{METODE}

Penelitian ini dilaksanakan di Stasiun Kereta Api Gambir. Waktu pengambilan data adalah pada hari Sabtu, 22 Maret 2017 dan Sabtu, 13 Mei 2017. Metode penelitian ini adalah kualitatif sesuai dengan konteks pengambilan data, dengan melibatkan peran serta peneliti dalam penentuan kriteria dan proses analisisnya.

Teknik Pengambilan Data yang digunakan pada penelitian ini adalah: a. Literatur

Literatur digunakan untuk pengumpulan landasan teori yang digunakan atau dasar pada jurnal penelitian ini.

b. Angket atau kuesioner

Instrumen angket atau kuesioner dalam penelitian ini menggunakan skala kuantitatif, maka variabel yang diukur dijabarkan menjadi indikator-indikator yang dapat diukur. Indikator tersebut digunakan berupa pertanyaan atau pernyataan yang perlu dijawab oleh responden. Setiap jawaban dihubungkan dengan bentuk pernyataan atau dukungan sikap yang diungkapan dengan memberi tanda pada pilihan jawaban yang terdiri dari, setuju, netral dan tidak setuju.

\section{HASIL DAN PEMBAHASAN}

Masyarakat yang menggunakan fasilitas stasiun kereta api di stasiun gambir tentunya akan menempuh perjalanan yang cukup jauh dan lama. Oleh karena itu fasilitas toilet yang terdapat dalam stasiun harus dibuat sesuai dengan standar sehingga dapat dipergunakan oleh pengunjung stasiun dengan nyaman saat menunggu di stasiun.

Berikut adalah hasil dari angket yang kami sebar dengan pertanyaan "Signage (papan penunjuk arah) sudah cukup jelas memberikan keterangan mengenai tujuan." 
Tabel 1. Kejelasan Signage

\begin{tabular}{|c|c|c|c|}
\hline \multicolumn{2}{|c|}{ Laki-Laki } & Perempuan & Jumlah \\
\hline \multicolumn{2}{|c|}{18} & 12 & 30 \\
\hline $\begin{array}{c}\text { Tidak } \\
\text { Setuju }\end{array}$ & Netral & Setuju & Jumlah \\
\hline $2(7 \%)$ & $1(3 \%)$ & $27(90 \%)$ & 30 \\
\hline \multicolumn{2}{|c|}{ Nilai Maksimal 100\% } & 30 \\
\hline
\end{tabular}

Dari angka di atas dapat diketahui bahwa 90\% pengunjung berpendapat bahwa signage di Stasiun Gambir memberikan infomasi yang jelas mengenai arah.

Jika dilihat dari standar yang sudah ditetapkan oleh Gerakan Nasional Standarisasi Toilet Umum Indonesia (Adiwoso, 2016), penggunaan font pada signage bukan font yang ditetapkan oleh standar. Seharusnya penggunaan font pada signage menggunakan font Braille dan tidak ada signage toilet yang ramah untuk anak-anak.

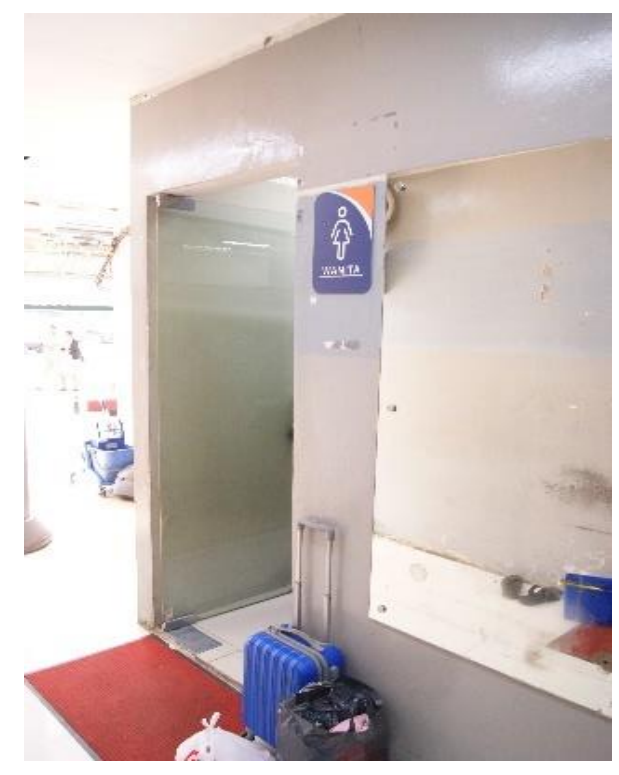

Gambar 1. Signage Toilet Kereta Api Gambir (Sumber: dokumentasi tim peneliti, 2017)

Papan penunjuk arah (signage) terpasang dengan baik sehingga dapat membantu penumpang untuk menemukan toilet terdekat dengan tempat mereka menunggu kereta di stasiun. Di lokasi terdapat signage dengan gambar kursi roda di atas tulisan toilet yang berarti terdapat fasilitas toilet untuk orang yang mengalami disabilitas. Namun setelah ditinjau kembali, tidak ditemukan fasilitas toilet untuk orang berkebutuhan khusus dan disabilitas. Hal ini sangat disayangkan karena pengunjung Stasiun Gambir sangat banyak dan terdiri dari semua kalangan masyarakat.

Berikut adalah hasil dari angket yang disebar dengan pertanyaan "Lebar lorong toilet sudah cukup untuk bergerak saat keadaan sepi maupun ramai."

Tabel 2. Lebar lorong toilet mencukupi untuk gerak

\begin{tabular}{|c|c|c|c|}
\hline $\begin{array}{c}\text { Tidak } \\
\text { Setuju }\end{array}$ & Netral & Setuju & Jumlah \\
\hline $8(27 \%)$ & $4(3 \%)$ & $18(60 \%)$ & 30 \\
\hline \multicolumn{3}{|c|}{ Nilai Maksimal 100\% } & 30 \\
\hline
\end{tabular}

Dari angka di atas dapat diketahui $60 \%$. Ditemukan hasil akhir bahwa $60 \%$ pengguna kereta di stasiun gambir sudah merasa nyaman dengan lebar lorong yang ada di toilet stasiun.

Lorong yang terdapat di dalam toilet berbentuk memanjang sesuai dengan peletakkan urinoir (di sebelah kiri gambar) dan kubikal toilet (di sebelah kanan gambar). Luas lorong cukup untuk jalur keluar masuk pengguna sehingga suasana dalam toilet tidak 
terlalu sempit dan berhimpitan baik untuk pengguna urinoir dan kubikal.

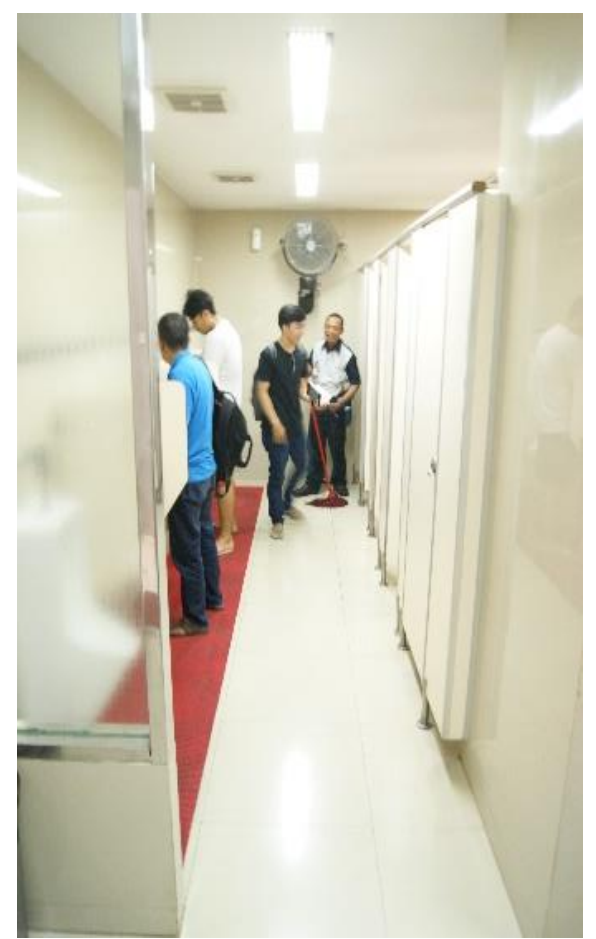

Gambar 2. Lorong Toilet Stasiun Kereta Api Gambir (Sumber: dokumentasi tim peneliti, 2017)

Pemakaian keramik dan dinding berwarna putih menimbulkan kesan bersih dan nyaman saat pengguna sedang berada dalam toilet. Keramik selalu dibersihkan oleh pengurus toilet sehingga lantai tetap terlihat bersih dan nyaman untuk digunakan.

Berikut adalah hasil dari angket yang kami sebar dengan pertanyaan "Luas ruang untuk toilet duduk sudah cukup untuk bergerak."

Tabel 3. Luasan toilet duduk mencukupi untuk gerak

\begin{tabular}{|c|c|c|c|}
\hline $\begin{array}{c}\text { Tidak } \\
\text { Setuju }\end{array}$ & Netral & Setuju & Jumlah \\
\hline $16(53 \%)$ & $4(13 \%)$ & $10(33 \%)$ & 30 \\
\hline \multicolumn{2}{|c|}{ Nilai Maksimal 100\% } & 30 \\
\hline
\end{tabular}

Dari angka di atas dapat diketahui bahwa $53 \%$ pengguna kereta api di stasiun gambir merasa luas ruangan dalam ruang kubikan kurang leluasa untuk bergerak dan melakukan aktifitas.

Kubikal dalam toilet digunakan sebagai pemisah ruang untuk fasilitas toilet duduk. Setiap satu kubikal diisi oleh satu toilet duduk.

Jika dilihat dari standar yang sudah ditetapkan oleh Gerakan Nasional Standarisasi Toilet Umum Indonesia (Adiwoso, 2016), ukuran ruang cubicle pada toilet stasiun kereta api Gambir memenuhi 2 dari 3 kriteria untuk kategori nyaman. Namun demikian tidak ditemukan adanya toilet khusus difabel di Stasiun Gambir.

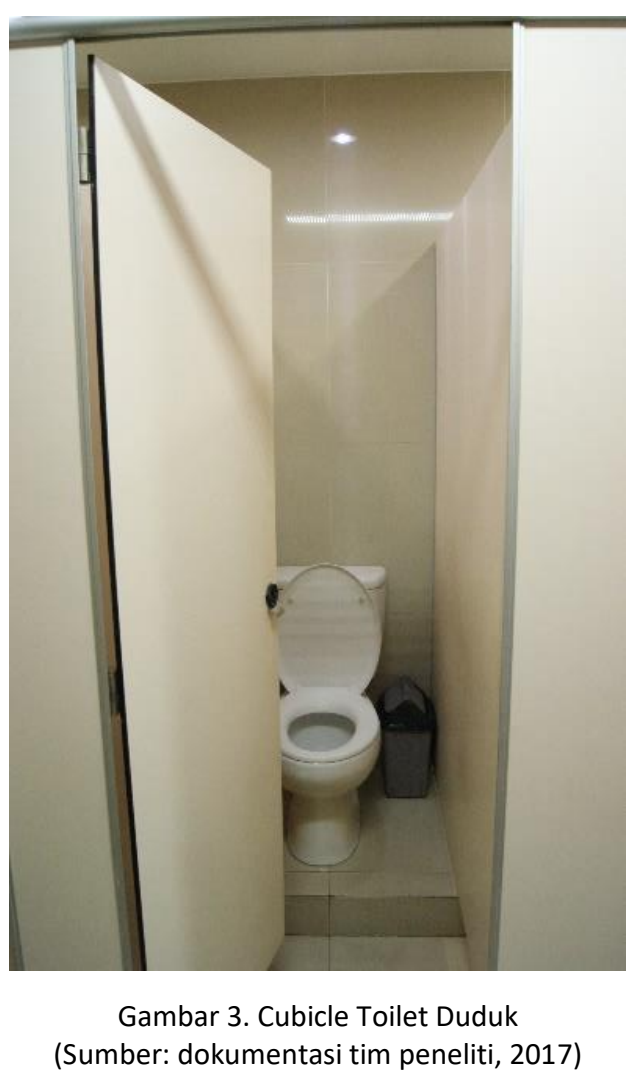


Namun luas ruangan kubikal ini tidak cukup ergonomis dikarenakan ukuran ruang yang cukup kecil. Pengguna dengan ukuran tubuh yang besar (oversize) dan pengguna kursi roda tidak dapat menggunakan toilet kubikal dengan baik. Akibatnya mereka harus dengan terpaksa menggunakan urinoir yang disediakan, bahkan ada yang harus menunggu sampai kereta mereka datang sehingga dapat menggunakan fasilitas toilet yang berada di dalam kereta api.

Berikut adalah hasil dari angket yang kami sebar dengan pertanyaan "Ketinggian wastafel mudah dijangkau orang dewasa maupun anak-anak."

Tabel 4. Ketinggian wastafel terjangkau

\begin{tabular}{|c|c|c|c|}
\hline Tidak Setuju & Netral & Setuju & Jumlah \\
\hline $21(70 \%)$ & $5(17 \%)$ & $4(13 \%)$ & 30 \\
\hline \multicolumn{2}{|c|}{ Nilai Maksimal 100\% } & 30 \\
\hline
\end{tabular}

Dari angka di atas dapat diketahui bahwa 70\% dari responden memberikan penilaian bahwa wastafel sulit dijangkau.

Jika dilihat dari standar yang sudah ditetapkan oleh Gerakan Nasional Standarisasi Toilet Umum Indonesia (Adiwoso, 2016), ukuran wastafel sudah sesuai dengan standar yang sudah ditetapkan. Namun fasilitas toilet tidak menyediakan wastafel untuk anak-anak.

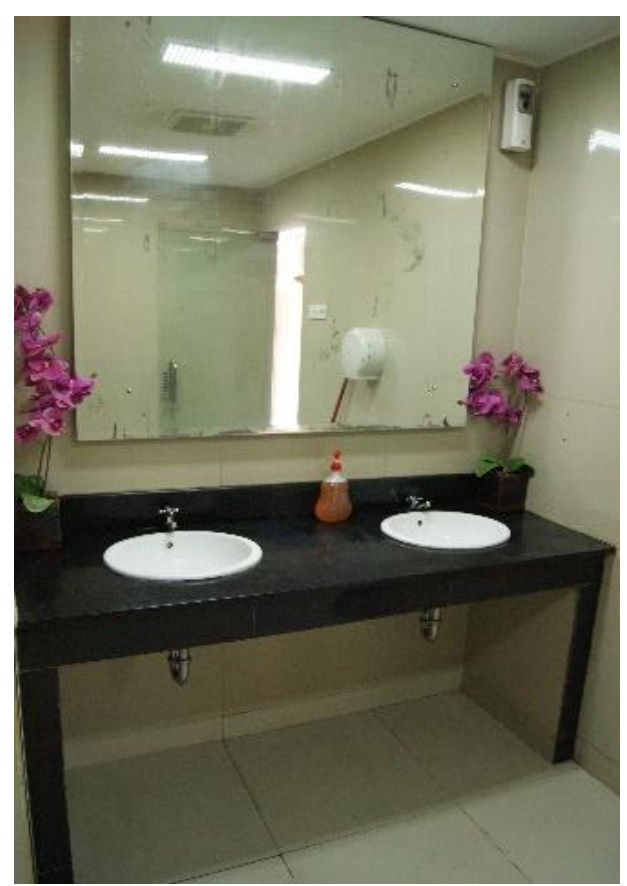

Gambar 4 Wastafel Toilet Stasiun Kereta Api Gambir (Sumber: dokumentasi tim peneliti, 2017)

Material yang digunakan adalah marmer sehingga tahan bentur dengan barang-barang yang dibawa pengguna saat menggunakan fasilitas toilet. Meja wastafel menggunakan desain terbuka sehingga terlihat lebih ramping dan memudahkan petugas melakukan pengecekan maupun perbaikan bila terjadi kebocoran pada pipa wastafel. Di sisi lain desain ini mengakibatkan air yang bocor dapat memerciki pengguna wastafel.

Berikut adalah hasil dari angket yang kami sebar dengan pertanyaan "Ketinggian urinoir untuk orang dewasa sudah sesuai dan mudah digunakan."

Tabel 5. Ketinggian urinoir untuk orang dewasa sudah sesuai

\begin{tabular}{|c|c|c|c|}
\hline Tidak Setuju & Netral & Setuju & Jumlah \\
\hline 0 & $12(40 \%)$ & $18(60 \%)$ & 30 \\
\hline \multicolumn{3}{|c|}{ Nilai Maksimal 100\% } & 30 \\
\hline
\end{tabular}


Dari tabel tersebut di atas dapat disimpulkan bahwa $60 \%$ dari responden menilai urinoir untuk orang dewasa sudah sesuai dan mudah digunakan.

Jika dilihat dari standar yang sudah ditetapkan oleh Gerakan Nasional Standarisasi Toilet Umum Indonesia (Adiwoso, 2016), dimensi urinoir orang dewasa yang terdapat di stasiun kereta api Gambir ini belum sesuai dengan standar yang sudah ditetapkan. Dapat dilihat ukuran yang sudah kami teliti di toilet stasiun kereta api Gambir (gambar 5.), lebar urinoir menurut standar adalah $350 \mathrm{~mm}$. Dan tinggi urinoir yang sudah ditetapkan seharusnya mencapai $600 \mathrm{~mm}$.

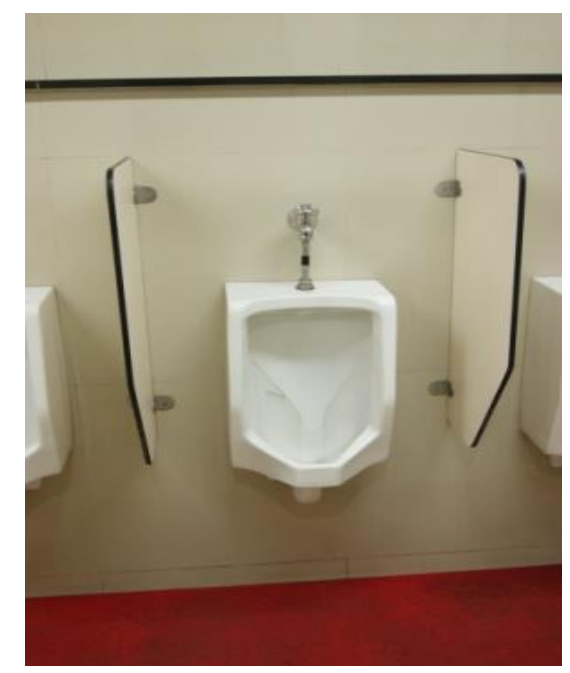

Gambar 5. Urinoir Dewasa

(Sumber: dokumentasi tim peneliti, 2017)

Berikut adalah hasil dari angket yang disebar dengan pertanyaan "Ketinggian urinoir untuk anak-anak sudah sesuai dan mudah digunakan."
Tabel 6. Ketinggian Urinoir untuk anak-anak sudah sesuai

\begin{tabular}{|c|c|c|c|}
\hline Tidak Setuju & Netral & Setuju & Jumlah \\
\hline 0 & $12(40 \%)$ & $18(60 \%)$ & 30 \\
\hline \multicolumn{3}{|c|}{ Nilai Maksimal 100\% } & 30 \\
\hline
\end{tabular}

Dari tabel tersebut dapat diketahui bahwa $60 \%$ responden menilai bahwa urinoir untuk anak-anak sudah sesuai dan mudah digunakan.

Jika dilihat dari standar yang sudah ditetapkan oleh Gerakan Nasional Standarisasi Toilet Umum Indonesia (Adiwoso, 2016), dimensi urinoir anak-anak yang terdapat di stasiun kereta api Gambir ini belum sesuai dengan standar yang sudah ditetapkan. Dapat dilihat lebar urinoir di toilet stasiun kereta api Gambir adalah 360mm. Dan tinggi urinoir yang sudah ditetapkan seharusnya mencapai $850 \mathrm{~mm}$. Urinoir untuk anak-anak seharusnya terletak menempel dengan lantai toilet sehingga anak-anak yang ingin menggunakan dapat meraihnya dengan mudah.

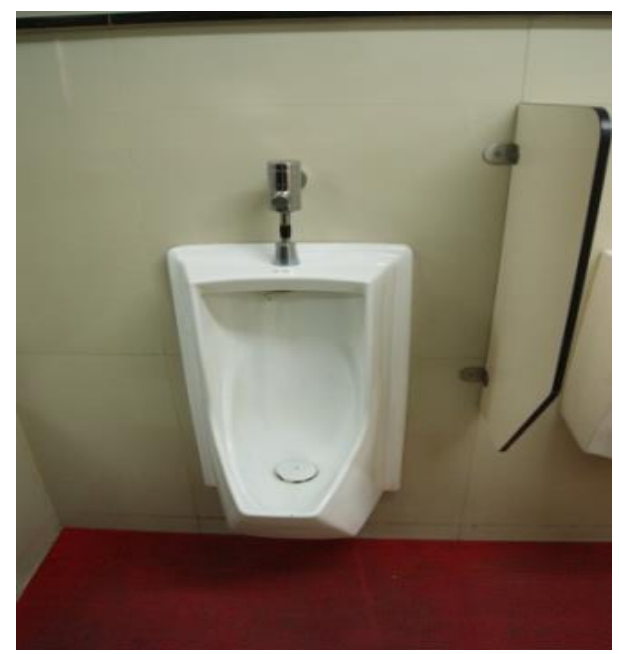

Gambar 6. Urinoir Anak-Anak (Sumber: dokumentasi tim peneliti, 2017) 
selanjutnya adalah hasil dari angket yang disebar dengan pertanyaan "Ketinggian toilet duduk sudah sesuai sehingga mudah untuk digunakan."

Tabel 7. Ketinggian toilet duduk sudah sesuai

\begin{tabular}{|c|c|c|c|}
\hline Tidak Setuju & Netral & Setuju & Jumlah \\
\hline $8(27 \%)$ & $4(13 \%)$ & $18(60 \%)$ & 30 \\
\hline \multicolumn{3}{|c|}{ Nilai Maksimal $100 \%$} & 30 \\
\hline
\end{tabular}

Dari tabel tersebut di atas dapat diketahui bahwa $60 \%$ dari responden menilai ketinggian toilet duduk sudah sesuai sehingga mudah untuk digunakan orang dewasa maupun anakanak. Namun demikian ditemukan $27 \%$ dari responden yang tidak setuju sehingga perlu dipertimbangkan untuk memberikan alternatif ketinggian yang berbeda untuk mengakomodasi pengguna toilet dengan ukuran tubuh yang berbeda.

Menurut standar yang sudah ditetapkan oleh Gerakan Nasional Standarisasi Toilet Umum Indonesia (Adiwoso, 2016), dimensi toilet duduk sudah sesuai dengan standar. Hal itu karena hampir semua produsen toilet duduk sudah mengikuti aturan standar yang ditentukan sehingga pengguna akan terasa nyaman saat menggunakan.

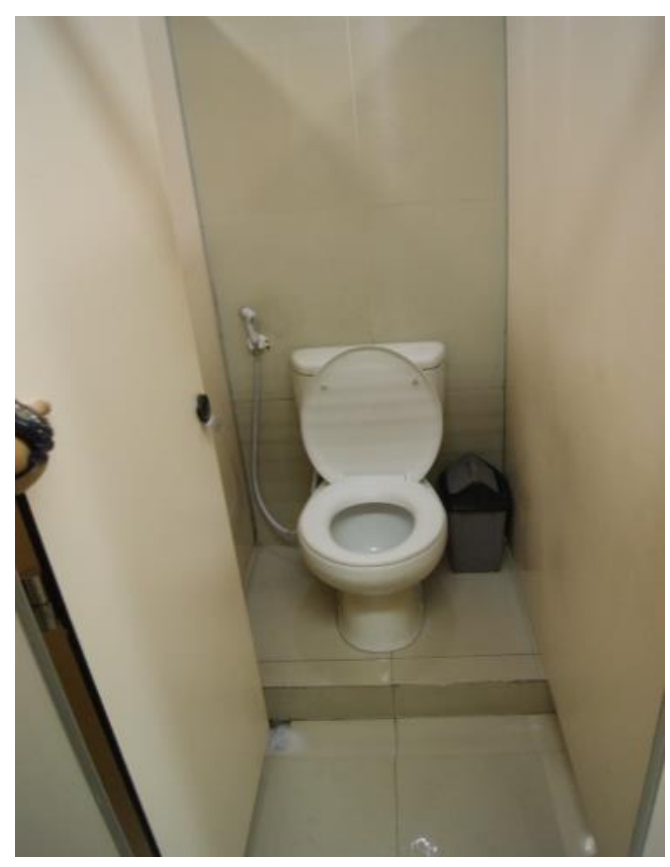

Gambar 7. Toilet Duduk Dalam Kubikel (Sumber: dokumentasi tim peneliti, 2017)

Dari pembahasan tersebut di atas, dapat diketahui bahwa beberapa kriteria yang dapat digunakan dalam penilaian kesesuaian toilet dengan prinsip dan kriteria desain universal adalah sebagai berikut: (1) Kejelasan signage; (2) Lebar lorong toilet leluasa untuk sirkulasi; (3) Luasan toilet mencukupi untuk gerak pengguna; (4) Ketinggian wastafel mudah dijangkau; (5) Ketinggian urinoir untuk orang dewasa sudah sesuai standar; (6) Ketinggian urinoir untuk anak-anak sudah sesuai standar.

\section{SIMPULAN}

Dari pembahasan mengenai toilet yang terdapat di Stasiun Gambir dapat diketahui bahwa: (1) $90 \%$ responden menyetujui adanya kejelasan signage; (2) $60 \%$ responden menyatakan bahwa lebar lorong 
toilet leluasa untuk sirkulasi; (3) $53 \%$ responden menyatakan bahwa luasan toilet tidak mencukupi untuk gerak pengguna; (4) $70 \%$ responden menyatakan bahwa ketinggian wastafel tidak mudah dijangkau; (5) $60 \%$ responden menyatakan bahwa ketinggian urinoir untuk orang dewasa sudah sesuai; (6) $60 \%$ ketinggian urinoir untuk anak-anak sudah sesuai.

Sehingga dapat disimpulkan bahwa diperlukan perbaikan terhadap toilet di Stasiun Gambir untuk dapat memenuhi prinsip dan kriteria desain universal, seperti memberikan alternatif tinggi toilet untuk mengakomodasi pengguna yang berbeda. Selain itu juga diperlukan wastafel dengan ketinggian yang disesuaikan dengan ukuran anak-anak sehingga memudahkan penggunaannya. Ukuran kubikel juga tidak memberikan keleluasan gerak di dalam toilet sehingga menyulitkan pengguna.

Penelitian lebih lanjut dapat dilakukan di Stasiun Gambir pada area lainnya terkait dengan kebutuhan kaum difabel, anak-anak maupun lansia yang merupakan pengguna Stasiun Gambir sehingga memenuhi prinsip dan kriteria desain universal.

\section{DAFTAR PUSTAKA}

Adiwoso, N. (2016). Toilet Umum Indonesia. Jakarta: Asosiasi Toilet Indonesia.
Keumala, C. N. (2016). Pengaruh Konsep Desain Universal Terhadap Tingkat Kemandirian Difabel: Studi Kasus Masjid UIN Sunan Kalijaga dan Masjid Kampus Universitas Gajah Mada. Inklusi: Journal of Disability Studies, 19-39.

Muhammad Idrus. Metode Penelitian IImu Sosial. Yogyakarta: Erlangga, 2009.

Wolfgang F.E Preiser. Universal Design Handbook. The McGraw-Hill Companies, Inc, 2011.

Yanti, I. P. (2018). Implementasi Universal Design Pada Fasilitas Pendidikan Tinggi. Jurnal Arsitektur dan Perencanaan, 223-239.

http://bilic.idp-europe.org/divisi-aksesibilitasdiskusi-desain-universal.html

https://www.academia.edu/4789743/Univers al Desain Sebuah Pendekatan Desain u ntuk Menjawab Keberagaman

http://journal.itb.ac.id/download.php?file=D0 8074. pdf\&id=370\&up=9.

https://www.slideshare.net/alvinoyeah/maka lah-universal-design-oleh-m-razqialvinagung-1270121009

https://toillege.wordpress.com/2013/09/25/d efinisi-standar-toilet/

http://www.brailleauthority.org/sizespacingof braille/sizespacingofbraille.pdf

https://www.slideshare.net/dedyparch/astandard-toilet-umum 